\title{
On Lower Separation and Regularity Axioms in Fuzzy Topological Spaces
}

\author{
Amin Saif and Adem Kılıçman \\ Department of Mathematics and Institute for Mathematical Research, University Putra Malaysia, UPM, Serdang, \\ Selangor 43400, Malaysia \\ Correspondence should be addressed to Adem Kılıçman, akilicman@putra.upm.edu.my
}

Received 16 July 2010; Revised 10 December 2010; Accepted 4 January 2011

Academic Editor: E. E. Kerre

Copyright (C) 2011 A. Saif and A. Kılıçman. This is an open access article distributed under the Creative Commons Attribution License, which permits unrestricted use, distribution, and reproduction in any medium, provided the original work is properly cited.

We use the concepts of the quasicoincident relation to introduce and investigate some lower separation axioms such as $\alpha T_{0}, \alpha T_{1}$, $\alpha T_{1 / 2}$, and $\alpha T_{2}$ as well as the regularity axioms $\alpha R_{0}$ and $\alpha R_{1}$. Further we study some of their properties and the relations among them in the general framework of fuzzy topological spaces.

\section{Introduction}

The fundamental concept of a fuzzy set was introduced by Zadeh in 1965, [1]. Subsequently, in 1968, Chang [2] introduced fuzzy topological spaces (in short, fts). In Chang's fuzzy topological spaces, each fuzzy set is either open or not. Later on, Chang's idea was developed by Goguen [3], who replaced the closed interval $I=[0,1]$ by a more general lattice L. In 1985, Kubiak [4], and Šostak [5], in separated works, made topology itself fuzzy besides their dependence on fuzzy sets. In 1991, from a logical point of view, Ying [6] studied Hohles topology and called it fuzzifying topology. This fuzzification opened a rich field for research. As it is well known, the neighborhood structure is not suitable to I-topology, and $\mathrm{Pu}$ and Liu [7] broke through the classical theory of neighborhood system and established the strong and powerful method of quasicoincident neighborhood system in I-topology. Zhang and $\mathrm{Xu}[8]$ established the neighborhood structure in fuzzifying topological spaces. Considering the completeness and usefulness of theory of $I$-fuzzy topologies, Fang [9] established I-fuzzy quasicoincident neighborhood system in $I$-fuzzy topological spaces and gave a useful tool to study $I$-fuzzy topologies.

In ordinary topology, $\alpha$-open sets were introduced and studied by Njastad [10]. Bin Shahna [11], in the same spirit, defined fuzzy $\alpha$-open and fuzzy $\alpha$-closed. Separation is an essential part of fuzzy topology, on which a lot of work has been done. In the framework of fuzzifying topologies, Shen [12], Yue and Fang [13], Li and Shi [14], and Khedr et al. [15] introduced some separation axioms and their separation axioms are discussed on crisp points not on fuzzy points. In 2004, Mahmoud et al. [16] introduced fuzzy semicontinuity and fuzzy semiseparation axioms and examined the validity of some characterization of these concepts. Further, they also defined fuzzy generalized semiopen set and introduced fuzzy separation axioms by using thew semiopen sets concept. In the same paper, the authors also discussed fuzzy semiconnected and fuzzy semicompact spaces and some of their properties.

The present paper is organized as follows. It consists of four sections. After this introduction, Section 2 is devoted to some preliminaries. In Section 3, we introduce the notions of some lower separation axioms such as the $\alpha T_{0}, \alpha T_{1}, \alpha T_{1 / 2}$, and $\alpha T_{2}$ axioms with instigating some of their properties and the relations between them in the general framework of fuzzy topological spaces. In Section 4, we introduce the notions of some lower regularity axioms such as the $\alpha R_{0}$ and $\alpha R_{1}$ with instigating some of their properties and the relations between them in the general framework of fuzzy topological spaces. 


\section{Preliminaries}

Throughout this paper, $X$ represents a nonempty fuzzy set and fuzzy subset $A$ of $X$, denoted by $A \leq X$, then it is characterized by a membership function in the sense of Zadeh [1]. The basic fuzzy sets are the empty set, the whole set, and the class of all fuzzy sets of $X$ which will be denoted by $0_{X}, 1_{X}$, and $I^{X}$, respectively. A subfamily $\tau$ of $I^{X}$ is called a fuzzy topology described by Chang [2]. Moreover, the pair $(X, \tau):=\left(I^{X}, \tau\right)$ will be meant as a fuzzy topological space, on which no separation axioms are assumed unless explicitly stated. The fuzzy closure, the fuzzy interior, and the fuzzy complement of any set $A$ in $(X, \tau)$ are denoted by $\mathrm{Cl}(A)$, $\operatorname{Int}(A)$, and $1-A$, respectively. A fuzzy set which is a fuzzy point [17] with support $x \in X$ and value $t(0<t \leq 1)$ is denoted by $x_{t}$, and $\operatorname{Pt}(X)$ will denote the family of all point fuzzy sets $x_{t} \in I^{X}$. For any two fuzzy sets $A$ and $B$ in $(X, \tau)$, $A \leq B$ if and only if $A(x) \leq B(x)$ for each $x \in X$.

Definition 1 (see [18]). In a fuzzy topological space $(X, \tau)$, a fuzzy set $A$ is called a quasicoincident with a fuzzy set $B$, denoted by $A q B$, if $A(x)+B(x)>1$ for some $x \in X$. A fuzzy point $x_{t} \leq A$ is called quasicoincident with the fuzzy set $A$, denoted by $x_{t} q A$, if $t+A(x)>1$. Relation "does not quasicoincide with" or "not quasicoincident with" is denoted by $\neg q$. A fuzzy set $A$ in $(X, \tau)$ is called quasi-neighborhood of $x_{t}$ if there is a fuzzy open set $U$ such that $x_{t} q U \leq A$.

Definition 2 (see [11]). A fuzzy subset A of a fuzzy topological space $(X, \tau)$ is said to be fuzzy $\alpha$-open set in $(X, \tau)$ if $A \leq \operatorname{Int}(\mathrm{Cl}(\operatorname{Int}(A)))$ and the fuzzy complement of fuzzy $\alpha$ open set is fuzzy $\alpha$-closed set.

$F \alpha O(X, \tau)$ will denote the family of all fuzzy $\alpha$-open sets in $(X, \tau)$, and $F \alpha C(X, \tau)$ will denote the family of all fuzzy $\alpha$-closed sets in $(X, \tau)$.

Definition 3 (see [11]). Let $A$ be a fuzzy set in fuzzy topological space $(\mathrm{X}, \tau)$. $\operatorname{Int}_{\alpha}(A)=\bigvee\{B \in F \alpha O(X, \tau)$ : $B \leq A\}$ is called the $\alpha$-interior of $A$, and $\mathrm{Cl}_{\alpha}(\mathrm{A})=\bigwedge\{B \in$ $F \alpha C(X, \tau): A \leq B\}$ is called the $\alpha$-closure of $\mathrm{A}$.

Theorem 1 (see [11]). Let $(X, \tau)$ be a fuzzy topological space, and let $A, B$ be two fuzzy sets in X. Then the following holds.

(1) $A \leq \mathrm{Cl}_{\alpha}(A)$.

(2) $A \in F \alpha O(X, \tau)$ if and only if $A=\mathrm{Cl}_{\alpha}(A)$.

(3) If $A \leq B$, then $\mathrm{Cl}_{\alpha}(A) \leq \mathrm{Cl}_{\alpha}(B)$.

(4) $\mathrm{Cl}_{\alpha}(A \vee B)=\mathrm{Cl}_{\alpha}(A) \vee \mathrm{Cl}_{\alpha}(B)$.

(5) $\mathrm{Cl}_{\alpha}(A \wedge B) \leq \mathrm{Cl}_{\alpha}(A) \wedge \mathrm{Cl}_{\alpha}(B)$.

\section{3. $\alpha$-Separation Axioms}

In this section, we introduce the notions of some lower separation axioms such as the $\alpha T_{0}, \alpha T_{1}, \alpha T_{1 / 2}$, and $\alpha T_{2}$ axioms. Furthermore, we instigate some of their properties and the relations between them in the general framework of fuzzy topological spaces.
Definition 4. A fuzzy topological space $(X, \tau)$ is called

(1) fuzzy $\alpha T_{0}$-space if for every pair of fuzzy points $x_{t}, y_{r}$ in $X(x \neq y)$, there exist $U \in F \alpha O(X, \tau)$ such that $x_{t} q U \leq 1-y_{r}$ or $y_{r} q U \leq 1-x_{t}$,

(2) fuzzy $\alpha T_{1}$-space if for every pair of fuzzy points $x_{t}, y_{r}$ in $X(x \neq y)$, there exist $U, V \in F \alpha O(X, \tau)$ such that $x_{t} q U \leq 1-y_{r}$ and $y_{r} q V \leq 1-x_{t}$,

(3) fuzzy $\alpha T_{2}$-space if for every pair of fuzzy points $x_{t}, y_{r}$ in $X(x \neq y)$, there exist $U, V \in F \alpha O(X, \tau)$ such that $x_{t} q U \leq 1-y_{r}, y_{r} q V \leq 1-x_{t}$ and $U \neg q V$.

Theorem 2. Let $(X, \tau)$ be a fuzzy topological space. If $(X, \tau)$ is fuzzy $\alpha T_{i}$-space, then it is fuzzy $\alpha T_{i-1}$-space, where $i=1,2$.

Proof. Obvious.

Theorem 3. A fuzzy topological space $(X, \tau)$ is fuzzy $\alpha T_{0}$-space if and only if for every pair of fuzzy points $x_{t}, y_{r}$ in $X(x \neq y)$, $\mathrm{Cl}_{\alpha}\left(x_{t}\right) \neq \mathrm{Cl}_{\alpha}\left(y_{r}\right)$.

Proof. Suppose that $(X, \tau)$ is $\alpha T_{0}$-space. Then for every pair of fuzzy points $x_{t}, y_{r}$ in $X(x \neq y)$, there exists $U \in$ $F \alpha O(X, \tau)$ such that $x_{t} q U \leq 1-y_{r}$ or $y_{r} q U \leq 1-x_{t}$. If $x_{t} q U \leq 1-y_{r}$, then $x_{t} \not 1-U$ and $U \leq 1-y_{r}$, that is, $x_{t} \not \leq 1-U$ and $y_{r} \leq 1-U$. Since $1-U$ is fuzzy $\alpha$-closed and $\mathrm{Cl}_{\alpha}\left(y_{r}\right)$ is the smallest fuzzy $\alpha$-closed containing $y_{r}$, then $\mathrm{Cl}_{\alpha}\left(y_{r}\right) \leq 1-U$. Since $x_{t} \not \leq 1-U$ and $x_{t} \leq \mathrm{Cl}_{\alpha}\left(x_{t}\right)$, then $\mathrm{Cl}_{\alpha}\left(x_{t}\right) \neq \mathrm{Cl}_{\alpha}\left(y_{r}\right)$.

Conversely, suppose that $x_{t}, y_{r}$ be a pair of fuzzy points in $X$ with $(x \neq y)$ and $\mathrm{Cl}_{\alpha}\left(x_{t}\right) \neq \mathrm{Cl}_{\alpha}\left(y_{r}\right)$. Let $z_{\lambda} \in \operatorname{Pt}(X)$ such that $z_{\lambda} \leq \mathrm{Cl}_{\alpha}\left(x_{t}\right)$ and $z_{\lambda} \not \leq \mathrm{Cl}_{\alpha}\left(y_{r}\right)$. We claim that $x_{t} \not \leq$ $\mathrm{Cl}_{\alpha}\left(y_{r}\right)$. For, if $x_{t} \leq \mathrm{Cl}_{\alpha}\left(y_{r}\right)$, then $\mathrm{Cl}_{\alpha}\left(x_{t}\right) \not \leq \mathrm{Cl}_{\alpha}\left(y_{r}\right)$. This contradicts the fact that $z_{\lambda} \not \mathrm{Cl}_{\alpha}\left(y_{r}\right)$. Hence $x_{t} \not \mathrm{Cl}_{\alpha}\left(y_{r}\right)$, that is, $x_{t} q\left(1-\mathrm{Cl}_{\alpha}\left(y_{r}\right)\right)$. And since $U:=1-\mathrm{Cl}_{\alpha}\left(y_{r}\right) \in$ $F \alpha O(X, \tau)$ and $1-y_{r} \leq 1-\mathrm{Cl}_{\alpha}=U$, then $x_{t} q U \leq 1-y_{r}$. That is, $(X, \tau)$ is fuzzy $\alpha T_{0}$-space.

Theorem 4. A fuzzy topological space $(X, \tau)$ is fuzzy $\alpha T_{1}$-space if and only if every singleton fuzzy points $x_{t}$ in $X$ is fuzzy $\alpha$ closed in $X$.

Proof. Suppose that $(X, \tau)$ is $\alpha T_{1}$-space. Let $y_{r} \leq 1-$ $x_{t}(x \neq y)$. Then there exist $U, V^{y} \in F \alpha O(X, \tau)$ such that $x_{t} q U \leq 1-y_{r}$ and $y_{r} q V^{y} \leq 1-x_{t}$. In part $y_{r} q V^{y} \leq 1-x_{t}$, we have $V^{y} \leq 1-x_{t}$. Let $A=\bigvee\left\{V^{y}: y_{r} q\left(1-x_{t}\right)\right\}$. One may easily verify that $A=1-x_{t}$. Hence $1-x_{t}$ is fuzzy $\alpha$-open set, that is, $x_{t}$ is fuzzy $\alpha$-open set.

Conversely, let $x_{t}, y_{r}$ be a pair of fuzzy points in $X$ with $(x \neq y)$. Then $x_{t}$ and $y_{r}$ are fuzzy $\alpha$-closed sets. Consequently, $1-x_{t}$ and $1-y_{r}$ are fuzzy $\alpha$-open sets. Hence $y_{r} q\left(1-x_{t}\right) \leq$ $\left(1-x_{t}\right)$ and $x_{t} q\left(1-y_{r}\right) \leq\left(1-y_{r}\right)$. Therefore, $(X, \tau)$ is fuzzy $\alpha T_{1}$-space.

Definition 5. A fuzzy subset $A$ of fuzzy topological space $(X, \tau)$ is called fuzzy $\alpha$-symmetric if for every pair of fuzzy points $x_{t}, y_{r}$ in $X, x_{t} \leq \mathrm{Cl}_{\alpha}\left(y_{r}\right)$ implies $y_{r} \leq \mathrm{Cl}_{\alpha}\left(x_{t}\right)$ (i.e., $x_{t} \leq \mathrm{Cl}_{\alpha}\left(y_{r}\right)$ implies $\mathrm{Cl}_{\alpha}\left(y_{r}\right)=\mathrm{Cl}_{\alpha}\left(x_{t}\right)$ ). 
Definition 6. A fuzzy subset $A$ of fuzzy topological space $(X, \tau)$ is called fuzzy $\alpha$-generalized closed set in $X$ (briefly $\alpha$ $g$-closed) if $\mathrm{Cl}_{\alpha}(A) \leq U$ whenever $A \leq U$ and $U \in F \alpha O(X, \tau)$.

We easily observe that every fuzzy $\alpha$-closed set is fuzzy $\alpha$-g-closed set.

Theorem 5. A fuzzy topological space $(X, \tau)$ is fuzzy $\alpha$ symmetric if and only if for every fuzzy point $x_{t}$ in $X$ is fuzzy $\alpha$-g-closed set.

Proof. Suppose that $(X, \tau)$ is fuzzy $\alpha$-symmetric and suppose that $x_{t} \leq U \in F \alpha O(X, \tau)$ and $\mathrm{Cl}_{\alpha}\left(x_{t}\right) \not \leq U$. This implies that there is fuzzy point $y_{\mathrm{r}}$ in $X$ such that $y_{r} \leq \mathrm{Cl}_{\alpha}\left(x_{t}\right) \wedge$ $(1-U)$. Then $y_{r} \leq \mathrm{Cl}_{\alpha}\left(x_{t}\right)$ and $y_{r} \leq(1-U)$, that is, $\mathrm{Cl}_{\alpha}\left(y_{r}\right) \leq \mathrm{Cl}_{\alpha}(1-U)=1-U$. Since $(X, \tau)$ is fuzzy $\alpha$ symmetric and $y_{r} \leq \mathrm{Cl}_{\alpha}\left(x_{t}\right)$, then $x_{t} \leq \mathrm{Cl}_{\alpha}\left(y_{r}\right) \leq 1-U$. But this is a contradiction with $x_{t} \leq U$ and $t \in(0,1]$. Hence, $\mathrm{Cl}_{\alpha}\left(x_{t}\right) \leq U$.

Conversely, suppose that for every fuzzy point $x_{t}$ in $X$ is fuzzy $\alpha$-g-closed set. Suppose that $x_{t} \leq \mathrm{Cl}_{\alpha}\left(y_{r}\right)$ and $y_{r} \not \leq$ $\mathrm{Cl}_{\alpha}\left(x_{t}\right)$. That is, $y_{r} \leq 1-\mathrm{Cl}_{\alpha}\left(x_{t}\right)$. Since $1-\mathrm{Cl}_{\alpha}\left(x_{t}\right) \in$ $F \alpha O(X, \tau)$ and $y_{r}$ is a fuzzy $\alpha$ - $g$-closed set, then $\operatorname{Cl}_{\alpha}\left(y_{r}\right) \leq$ $1-\mathrm{Cl}_{\alpha}\left(x_{t}\right)$. This implies that $x_{t} \leq 1-\mathrm{Cl}_{\alpha}\left(x_{t}\right) \leq 1-x_{t}$. This is a contradiction. Hence $(X, \tau)$ is fuzzy $\alpha$-symmetric.

Corollary 1. If fuzzy topological space $(X, \tau)$ is fuzzy $\alpha T_{1}$ space, then it is $\alpha$-symmetric.

Proof. By Theorem 4 , in fuzzy $\alpha T_{1}$-space $(X, \tau)$, every fuzzy point is fuzzy $\alpha$-closed set. By facts, every fuzzy $\alpha$-closed set is fuzzy $\alpha$ - $g$-closed set, and by Theorem $5,(X, \tau)$ is fuzzy $\alpha$ symmetric.

Corollary 2. A fuzzy topological space $(X, \tau)$ is fuzzy $\alpha$ symmetric and fuzzy $\alpha T_{0}$-space if and only if it is fuzzy $\alpha T_{1}$ space.

Proof. If $(X, \tau)$ is fuzzy $\alpha T_{1}$-space, then by Theorem 2 and Corollary 1, it is fuzzy $\alpha$-symmetric and fuzzy $\alpha T_{0}$-space. Conversely, suppose that $x_{t}, y_{r}$ be a pair of fuzzy points in $X$ with $(x \neq y)$. Then by fuzzy $\alpha T_{0}$-space, we may assume that there exists $x_{t} q U \leq 1-y_{r}$ for some $U \in F \alpha O(X, \tau)$, hence $x_{t} \not \leq \mathrm{Cl}_{\alpha}\left(y_{r}\right)$, which implies, by $\alpha$-symmetric, $y_{r} \not \leq \mathrm{Cl}_{\alpha}\left(x_{t}\right)$. That is, $y_{r} q\left(1-\mathrm{Cl}_{\alpha}\left(x_{t}\right)\right) \leq 1-\mathrm{Cl}_{\alpha}\left(x_{t}\right) \leq 1-x_{t}$. Hence, $(X, \tau)$ is fuzzy $\alpha T_{1}$-space.

Definition 7. A fuzzy topological space $(X, \tau)$ is called fuzzy $\alpha T_{1 / 2}$-space if every $\alpha$ - $g$-closed set is $\alpha$-closed set.

Theorem 6. For fuzzy $\alpha$-symmetric topological space $(X, \tau)$, the following properties are equivalent:

(1) $(X, \tau)$ is fuzzy $\alpha T_{0}$-space;

(2) $(X, \tau)$ is fuzzy $\alpha T_{1 / 2}$-space;

(3) $(X, \tau)$ is fuzzy $\alpha T_{1}$-space.

Proof. Obvious.
Theorem 7. For fuzzy $\alpha$-symmetric topological space $(X, \tau)$, the following properties are equivalent:

(1) $(X, \tau)$ is fuzzy $\alpha T_{2}$-space;

(2) for every pair of fuzzy points $x_{t}, y_{r}$ in $X(x \neq y)$, there exists $U \in F \alpha O(X, \tau)$ such that $x_{t} q U \leq 1-y_{r}$ and $y_{r} \not \leq \mathrm{Cl}_{\alpha}(U)$;

(3) for every fuzzy point $x_{t}$ in $X, \wedge\left\{\mathrm{Cl}_{\alpha}(U): U \in F \alpha O(X\right.$, $\left.\tau), x_{t} \leq U\right\}=x_{t}$.

Proof. (1) $\rightarrow(2)$ : Let $x_{t}, y_{r}$ be a pair of fuzzy points in $X$ with $(x \neq y)$. Then there exist $U, V \in F \alpha O(X, \tau)$ such that $x_{t} q U \leq$ $1-y_{r}, y_{r} q V \leq 1-x_{t}$ and $U \neg q V$, hence, $x_{t} \leq U$. Since $U \leq$ $1-V$ and $1-V$ is fuzzy $\alpha$-closed, then $\mathrm{Cl}_{\alpha}(U) \leq \mathrm{Cl}_{\alpha}(1-V)=$ $1-v$. And since $y_{r} \not \leq 1-V$, then $y_{r} \not \leq \mathrm{Cl}_{\alpha}(U)$.

$(2) \rightarrow(3)$ : It is clear that

$$
x_{t} \leq \bigwedge\left\{\mathrm{Cl}_{\alpha}(U): U \in F \alpha O(X, \tau), x_{t} \leq U\right\} .
$$

Now if $x_{t} \neq y_{r}$, then there exists $U \in F \alpha O(X, \tau)$ such that $x_{t} q U \leq 1-y_{r}$ and $y_{r} \not \leq \mathrm{Cl}_{\alpha}(U)$. This implies that

$$
y_{r} \not \leq \bigwedge\left\{\mathrm{Cl}_{\alpha}(U): U \in F \alpha O(X, \tau), x_{t} \leq U\right\} .
$$

Hence

$$
\bigwedge\left\{\mathrm{Cl}_{\alpha}(U): U \in F \alpha O(X, \tau), x_{t} \leq U\right\}=x_{t} .
$$

$(3) \rightarrow(1)$ : Let $x_{t}, y_{r}$ be a pair of fuzzy points in $X$ with $(x \neq y)$. Since

$$
\bigwedge\left\{\mathrm{Cl}_{\alpha}(U): U \in F \alpha O(X, \tau), x_{t} \leq U\right\}=x_{t},
$$

then there is fuzzy $U \in F \alpha O(X, \tau)$ such that $x_{t} \leq U$ and $y_{r} \not \leq$ $\mathrm{Cl}_{\alpha}(U)$. Hence $x_{t} q U \leq \mathrm{Cl}_{\alpha}(U) \leq 1-y_{r}$. Put $V=1-\mathrm{Cl}_{\alpha}(U)$, then $y_{r} q V \leq 1-V \leq 1-x_{t}$ and it is clear that $V \neg U$. Hence $(X, \tau)$ is fuzzy $\alpha T_{2}$-space.

\section{4. $\alpha$-Regularity Axioms}

In this section, we introduce the notions of some lower regularity axioms such as the $\alpha R_{0}$ and $\alpha R_{1}$ with instigating some of their properties and the relations between them in the general framework of fuzzy topological spaces.

Definition 8. A fuzzy topological space $(X, \tau)$ is called fuzzy $\alpha R_{0}$-space if for every $U \in F \alpha O(X, \tau)$ and for every fuzzy point $x_{t} \leq U, \mathrm{Cl}_{\alpha}\left(x_{t}\right) \leq U$.

Theorem 8. A fuzzy topological space $(X, \tau)$ is fuzzy $\alpha R_{0}$-space if and only if for every pair of fuzzy points $x_{t}, y_{r}$ in $X$ with $(x \neq y)$ and $\mathrm{Cl}_{\alpha}\left(x_{t}\right) \neq \mathrm{Cl}_{\alpha}\left(y_{r}\right), \mathrm{Cl}_{\alpha}\left(x_{t}\right) \neg q \mathrm{Cl}_{\alpha}\left(y_{r}\right)$.

Proof. Suppose that a fuzzy topological space $(X, \tau)$ is fuzzy $\alpha R_{0}$-space. Let $x_{t}, y_{r}$ be a pair of fuzzy points in $X$ with $(x \neq y)$ and $\mathrm{Cl}_{\alpha}\left(x_{t}\right) \neq \mathrm{Cl}_{\alpha}\left(y_{r}\right)$. Then there exists fuzzy point $z_{\mu}$ in $X$ such that $z_{\mu} \leq \mathrm{Cl}_{\alpha}\left(x_{t}\right)$ and $z_{\mu} \not \leq \mathrm{Cl}_{\alpha}\left(y_{r}\right)$. If $x_{t} \leq$ $\mathrm{Cl}_{\alpha}\left(y_{r}\right)$, then $\mathrm{Cl}_{\alpha}\left(x_{t}\right) \leq \mathrm{Cl}_{\alpha}\left(y_{r}\right)$. Hence, $z_{\mu} \leq \mathrm{Cl}_{\alpha}\left(y_{r}\right)$, but this is a contradiction. Then $x_{t} \not \leq \mathrm{Cl}_{\alpha}\left(y_{r}\right)$, that is, $x_{t} \leq 1-\mathrm{Cl}_{\alpha}\left(y_{r}\right)$. Since $1-\mathrm{Cl}_{\alpha}\left(y_{r}\right)$ is fuzzy $\alpha$-open and $(X, \tau)$ is fuzzy $\alpha R_{0^{-}}$space, then $\mathrm{Cl}_{\alpha}\left(x_{t}\right) \leq 1-\mathrm{Cl}_{\alpha}\left(y_{r}\right)$. Hence $\mathrm{Cl}_{\alpha}\left(x_{t}\right) \neg q \mathrm{Cl}_{\alpha}\left(y_{r}\right)$. 
Conversely, Let $V \in F \alpha O(X, \tau)$ and $x_{t} \leq V$. We will prove that $\mathrm{Cl}_{\alpha}\left(x_{t}\right) \leq V$. Let $y_{r} \not \subset V$. Then $y_{r} \leq 1-V$ and $x \neq y$. This implies that $\mathrm{Cl}_{\alpha}\left(y_{r}\right) \leq \mathrm{Cl}_{\alpha}(1-V)=1-V$. Since $x_{t} \leq V$, then $x_{t} \not \mathrm{Cl}_{\alpha}$, that is, $\mathrm{Cl}_{\alpha}\left(x_{t}\right) \neq \mathrm{Cl}_{\alpha}\left(y_{r}\right)$. Then by assumption, $\mathrm{Cl}_{\alpha}\left(x_{t}\right) \neg q \mathrm{Cl}_{\alpha}\left(y_{r}\right)$. That is, $\mathrm{Cl}_{\alpha}\left(x_{t}\right) \leq$ $1-\mathrm{Cl}_{\alpha}\left(y_{r}\right) \leq V$. Hence $(X, \tau)$ is fuzzy $\alpha R_{0}$-space.

Definition 9. Let $A$ be a fuzzy subset of fuzzy topological space $(X, \tau)$. The fuzzy $\alpha$-kernel of $A$, denoted by $F \operatorname{Ker}_{\alpha}(A)$, is defined to be the set

$$
F \operatorname{Ker}_{\alpha}(A)=\bigwedge\{U \in F \alpha O(X, \tau): A \leq U\} .
$$

In particular, the fuzzy $\alpha$-kernel of fuzzy point $x_{t} \in P t(X)$ is defined to be the set

$$
F \operatorname{Ker}_{\alpha}\left(x_{t}\right)=\bigwedge\left\{U \in F \alpha O(X, \tau): x_{t} \leq U\right\} .
$$

Lemma 1. Let $(X, \tau)$ be a fuzzy topological space, and let $A$ be a fuzzy subset of $X$. Then

$$
F \operatorname{Ker}_{\alpha}(A)=\bigvee\left\{x_{t} \in \operatorname{Pt}(X): A q \mathrm{Cl}_{\alpha}\left(x_{t}\right)\right\}
$$

Proof. Suppose that $x_{t} \in \operatorname{Pt}(X)$ and $A \neg q \mathrm{Cl}_{\alpha}\left(x_{t}\right)$. Then $A \leq$ $1-\mathrm{Cl}_{\alpha}\left(x_{t}\right)$. Since $x_{t} \not \leq 1-\mathrm{Cl}_{\alpha}\left(x_{t}\right)$ and $1-\mathrm{Cl}_{\alpha}\left(x_{t}\right) \in F \alpha O(X, \tau)$ containing $A$, then $x_{t} \not \subset F \operatorname{Ker}_{\alpha}(A)$. That is,

$$
F \operatorname{Ker}_{\alpha}(A) \leq \bigvee\left\{x_{t} \in P t(X): A q \mathrm{Cl}_{\alpha}\left(x_{t}\right)\right\}
$$

Conversely, suppose that $x_{t} F \operatorname{Ker}_{\alpha}(A)$. That is, there is $U \in$ $F \alpha O(X, \tau)$ such that $A \leq U$ and $x_{t} \not \leq U$. Hence $x_{t} \leq 1-U$ which implies that

$$
\mathrm{Cl}_{\alpha}\left(x_{t}\right) \leq \mathrm{Cl}_{\alpha}(1-U)=1-U \leq 1-A .
$$

That is, $A q \mathrm{Cl}_{\alpha}\left(x_{t}\right)$. Hence $\bigvee\left\{x_{t} \in P t(X): A q \mathrm{Cl}_{\alpha}\left(x_{t}\right)\right\} \leq$ $F \operatorname{Ker}_{\alpha}(A)$.

Lemma 2. Let $(X, \tau)$ be a fuzzy topological space and $x_{t}, y_{r} \in$ $\operatorname{Pt}(X)$. Then $y_{r} \leq F \operatorname{Ker}_{\alpha}\left(x_{t}\right)$ if and only if $x_{t} \leq \mathrm{Cl}_{\alpha}\left(y_{r}\right)$.

Proof. Suppose that $x_{t} \leq \mathrm{Cl}_{\alpha}\left(y_{r}\right)$ and $y_{r} \not \leq F \operatorname{Ker}_{\alpha}\left(x_{t}\right)$. Then there is $U \in F \alpha O(X, \tau)$ such that $x_{t} \leq U$ and $y_{r} \not Z U$. Hence $y_{r} \leq 1-U$, which implies that $\mathrm{Cl}_{\alpha}\left(y_{r}\right) \leq \mathrm{Cl}_{\alpha}(1-U)=$ $1-U$. But this is a contradiction with $x_{t} \leq \mathrm{Cl}_{\alpha}\left(y_{r}\right)$ and $x_{t} \leq U$. Hence $y_{r} \leq F \operatorname{Ker}_{\alpha}\left(x_{t}\right)$. Conversely, suppose that $y_{r} \leq F \operatorname{Ker}_{\alpha}\left(x_{t}\right)$ and $x_{t} \not \mathrm{Cl}_{\alpha}\left(y_{r}\right)$. Then $x_{t} \leq 1-\mathrm{Cl}_{\alpha}\left(y_{r}\right) \in$ $F \alpha O(X, \tau)$. Since $y_{r} 1-\mathrm{Cl}_{\alpha}\left(y_{r}\right)$, then $y_{r} \leq F \operatorname{Ker}_{\alpha}\left(x_{t}\right)$. But this is a contradiction. Hence $x_{t} \leq \mathrm{Cl}_{\alpha}\left(y_{r}\right)$.

Lemma 3. Let $(X, \tau)$ be a fuzzy topological space and $x_{t}, y_{r} \in \operatorname{Pt}(X)$. Then $F \operatorname{Ker}_{\alpha}\left(x_{t}\right) \neq F \operatorname{Ker}_{\alpha}\left(y_{r}\right)$ if and only if $\mathrm{Cl}_{\alpha}\left(x_{t}\right) \neq \mathrm{Cl}_{\alpha}\left(y_{r}\right)$.

Proof. Suppose that $F \operatorname{Ker}_{\alpha}\left(x_{t}\right) \neq F \operatorname{Ker}_{\alpha}\left(y_{r}\right)$. Then there exists fuzzy point $z_{\mu}$ in $X$ such that $z_{\mu} \leq F \operatorname{Ker}_{\alpha}\left(x_{t}\right)$ and $z_{\mu} \not \leq F \operatorname{Ker}_{\alpha}\left(y_{r}\right)$. In the part $z_{\mu} \leq F \operatorname{Ker}_{\alpha}\left(x_{t}\right)$, by Lemma 2, $x_{t} q \mathrm{Cl}_{\alpha}\left(z_{\mu}\right)$. This implies that $x_{t} \leq \mathrm{Cl}_{\alpha}\left(z_{\mu}\right)$, that is, $\mathrm{Cl}_{\alpha}\left(x_{t}\right) \leq$ $\mathrm{Cl}_{\alpha}\left(z_{\mu}\right)$. And similarly, in the part $z_{\mu} \overleftrightarrow{ \pm} F \operatorname{Ker}_{\alpha}\left(y_{r}\right)$ we get $y_{r} \neg q \mathrm{Cl}_{\alpha}\left(z_{\mu}\right)$. This implies $y_{r} \not \mathrm{Cl}_{\alpha}\left(z_{\mu}\right)$. Since $\mathrm{Cl}_{\alpha}\left(x_{t}\right) \leq$ $\mathrm{Cl}_{\alpha}\left(z_{\mu}\right)$, then $y_{r} \not \leq \mathrm{Cl}_{\alpha}\left(x_{t}\right)$. Hence $\mathrm{Cl}_{\alpha}\left(x_{t}\right) \neq \mathrm{Cl}_{\alpha}\left(y_{r}\right)$.
Conversely, suppose that $\mathrm{Cl}_{\alpha}\left(x_{t}\right) \neq \mathrm{Cl}_{\alpha}\left(y_{r}\right)$. Then there exists fuzzy point $z_{\mu}$ in $X$ such that $z_{\mu} \leq \mathrm{Cl}_{\alpha}\left(x_{t}\right)$ and $z_{\mu} \not \leq$ $\mathrm{Cl}_{\alpha}\left(y_{r}\right)$. If $x_{t} \leq \mathrm{Cl}_{\alpha}\left(y_{r}\right)$, then $\mathrm{Cl}_{\alpha}\left(x_{t}\right) \leq \mathrm{Cl}_{\alpha}\left(y_{r}\right)$. Hence $z_{\mu} \leq$ $\mathrm{Cl}_{\alpha}\left(y_{r}\right)$ but this is a contradiction. Then $x_{t} \not \mathrm{Cl}_{\alpha}\left(y_{r}\right)$, that is, $x_{t} \leq 1-\mathrm{Cl}_{\alpha}\left(y_{r}\right)$. Hence $1-\mathrm{Cl}_{\alpha}\left(y_{r}\right) \in F \alpha O(X, \tau)$ containing $x_{t}$ and not $y_{r}$. Then $y_{r} \not F \operatorname{Ker}_{\alpha}\left(x_{t}\right)$ and $y_{r} \leq F \operatorname{Ker}_{\alpha}\left(y_{r} t\right)$. Hence $F \operatorname{Ker}_{\alpha}\left(x_{t}\right) \neq F \operatorname{Ker}_{\alpha}\left(y_{r}\right)$.

Theorem 9. A fuzzy topological space $(X, \tau)$ is fuzzy $\alpha R_{0}$-space if and only if for every pair of fuzzy points $x_{t}, y_{r}$ in $X$ with $(x \neq y)$ and $F \operatorname{Ker}_{\alpha}\left(x_{t}\right) \neq F \operatorname{Ker}_{\alpha}\left(y_{r}\right)$,

$$
F \operatorname{Ker}_{\alpha}\left(x_{t}\right) \neg q F \operatorname{Ker}_{\alpha}\left(y_{r}\right) .
$$

Proof. Suppose that a fuzzy topological space $(X, \tau)$ is $\alpha R_{0^{-}}$ space. Let $x_{t}, y_{r}$ be a pair of fuzzy points in $X$ with $(x \neq y)$ and $F \operatorname{Ker}_{\alpha}\left(x_{t}\right) \neq F \operatorname{Ker}_{\alpha}\left(y_{r}\right)$. By Lemma 3, $\mathrm{Cl}_{\alpha}\left(x_{t}\right) \neq \mathrm{Cl}_{\alpha}\left(y_{r}\right)$. Suppose that $F \operatorname{Ker}_{\alpha}\left(x_{t}\right) q F \operatorname{Ker}_{\alpha}\left(y_{r}\right)$ for some $z \in X$. Take

$$
\mu=F \operatorname{Ker}_{\alpha}\left(x_{t}\right)(z) \vee F \operatorname{Ker}_{\alpha}\left(y_{r}\right)(z) \in(0,1] .
$$

Then

$$
z_{\mu} \leq F \operatorname{Ker}_{\alpha}\left(x_{t}\right), \quad z_{\mu} \leq F \operatorname{Ker}_{\alpha}\left(y_{r}\right)
$$

In the part $z_{\mu} \leq F \operatorname{Ker}_{\alpha}\left(x_{t}\right)$, by Lemma 2 we get that $x_{t} \leq \mathrm{Cl}_{\alpha}\left(z_{\mu}\right)$, which implies $\mathrm{Cl}_{\alpha}\left(x_{t}\right) \leq \mathrm{Cl}_{\alpha}\left(z_{\mu}\right)$. Then by Theorem 8, $\mathrm{Cl}_{\alpha}\left(x_{t}\right)=\mathrm{Cl}_{\alpha}\left(z_{\mu}\right)$. Similarly, in the part $z_{\mu} \leq$ $F \operatorname{Ker}_{\alpha}\left(y_{r}\right)$, we get that $\mathrm{Cl}_{\alpha}\left(y_{r}\right)=\mathrm{Cl}_{\alpha}\left(z_{\mu}\right)=\mathrm{Cl}_{\alpha}\left(x_{t}\right)$. This is a contradiction. Therefore, $F \operatorname{Ker}_{\alpha}\left(x_{t}\right) \neg q F \operatorname{Ker}_{\alpha}\left(y_{r}\right)$.

Conversely, we will use Theorem 8 to prove that $(X, \tau)$ is fuzzy $\alpha R_{0}$-space. Let $x_{t}, y_{r}$ be a pair of fuzzy points in $X$ with $(x \neq y)$ and $\mathrm{Cl}_{\alpha}\left(x_{t}\right) \neq \mathrm{Cl}_{\alpha}\left(y_{r}\right)$. Then by Lemma 3, $F \operatorname{Ker}_{\alpha}\left(x_{t}\right) \neq F \operatorname{Ker}_{\alpha}\left(y_{r}\right)$. Hence by assumption, we get that $F \operatorname{Ker}_{\alpha}\left(x_{t}\right) \neg q F \operatorname{Ker}_{\alpha}\left(y_{r}\right)$. Suppose that $\mathrm{Cl}_{\alpha}\left(x_{t}\right) q \mathrm{Cl}_{\alpha}\left(y_{r}\right)$ for some $z \in X$. Take

$$
\mu=\mathrm{Cl}_{\alpha}\left(x_{t}\right)(z) \vee \mathrm{Cl}_{\alpha}\left(y_{r}\right)(z) \in(0,1]
$$

Then $z_{\mu} \leq \mathrm{Cl}_{\alpha}\left(x_{t}\right)$ and $z_{\mu} \leq \mathrm{Cl}_{\alpha}\left(y_{r}\right)$. Hence by Lemma 2, $x_{t} \leq F \operatorname{Ker}_{\alpha}\left(z_{\mu}\right)$ and $y_{r} \leq F \operatorname{Ker}_{\alpha}\left(z_{\mu}\right)$. Then by Lemma 1 ,

$$
F \operatorname{Ker}_{\alpha}\left(x_{t}\right) \leq F \operatorname{Ker}_{\alpha}\left(z_{\mu}\right), \quad F \operatorname{Ker}_{\alpha}\left(y_{r}\right) \leq F \operatorname{Ker}_{\alpha}\left(z_{\mu}\right) \text {, }
$$

that is,

$$
F \operatorname{Ker}_{\alpha}\left(x_{t}\right) q F \operatorname{Ker}_{\alpha}\left(z_{\mu}\right), \quad F \operatorname{Ker}_{\alpha}\left(y_{r}\right) q F \operatorname{Ker}_{\alpha}\left(z_{\mu}\right) \text {. }
$$

Hence by assumption,

$$
F \operatorname{Ker}_{\alpha}\left(x_{t}\right)=F \operatorname{Ker}_{\alpha}\left(z_{\mu}\right), \quad F \operatorname{Ker}_{\alpha}\left(y_{r}\right)=F \operatorname{Ker}_{\alpha}\left(z_{\mu}\right) \text {. }
$$

Hence $F \operatorname{Ker}_{\alpha}\left(x_{t}\right)=F \operatorname{Ker}_{\alpha}\left(y_{r}\right)$, that is, $F \operatorname{Ker}_{\alpha}\left(x_{t}\right) q F \operatorname{Ker}_{\alpha}\left(y_{r}\right)$. But this is a contradiction. Hence $\mathrm{Cl}_{\alpha}\left(x_{t}\right) \neg q \mathrm{Cl}_{\alpha}\left(y_{r}\right)$. Therefore, by Theorem $8,(X, \tau)$ is fuzzy $\alpha R_{0}$-space. 
Theorem 10. For fuzzy topological space $(X, \tau)$, the following properties are equivalent:

(1) $(X, \tau)$ is fuzzy $\alpha R_{0}$-space;

(2) for every fuzzy set $A \neq 0_{X}$ and $U \in F \alpha O(X, \tau)$ such that $A q U$, there exists $V \in F \alpha C(X, \tau)$ such that $A q V$ and $V \leq U$;

(3) for every $U \in F \alpha O(X, \tau), U=\bigvee\{V \in F \alpha O(X, \tau)$ : $V \leq U\}$

(4) for every $U \in F \alpha O(X, \tau), U=\bigwedge\{V \in F \alpha O(X, \tau)$ : $U \leq V\}$

(5) for every fuzzy point $x_{t} \in P t(X), \mathrm{Cl}_{\alpha}\left(x_{t}\right) \leq F \operatorname{Ker}_{\alpha}\left(x_{t}\right)$.

Proof. (1) $\rightarrow(2)$ : Let $A \neq 0_{X}$ be fuzzy set in $X$ and $U \in$ $F \alpha O(X, \tau)$ such that $A q U$ for some $z \in X$. Take $\mu=A(z) \vee$ $U(z)$. Then $z_{\mu} \leq A$ and $z_{\mu} \leq U$. Since $U \in F \alpha O(X, \tau)$ and $(X, \tau)$ is fuzzy $\alpha R_{0}$-space, then $\mathrm{Cl}_{\alpha}\left(z_{\mu}\right) \leq U$. Take $V=$ $\mathrm{Cl}_{\alpha}\left(z_{\mu}\right)$. Then $V \in F \alpha C(X, \tau)$ and $V \leq U$. Since $z_{\mu} \leq A$, then $\mathrm{Cl}_{\alpha}\left(z_{\mu}\right) q A$, that is, $A q V$.

$(2) \rightarrow(3)$ : It is clear that $\bigvee\{V \in F \alpha O(X, \tau): V \leq U\} \leq$ $U$. Let $x_{t} \leq U$. Since $U \in F \alpha O(X, \tau)$ and $x_{t} \neq 0_{X}$, then there exists $V \in F \alpha C(X, \tau)$ such that $x_{t} \leq V$ and $V \leq U$. Then $x_{t} \leq \bigvee\{V \in F \alpha O(X, \tau): V \leq U\}$, that is, $U \leq \bigvee\{V \in$ $F \alpha O(X, \tau): V \leq U\}$.

$(3) \rightarrow(4)$ : Obvious.

$(4) \rightarrow(5)$ : Let $x_{t} \in P t(X)$ and $y_{r} \not \leq F \operatorname{Ker}_{\alpha}\left(x_{t}\right)$. Then there exits $V \in F \alpha O(X, \tau)$ such that $x_{t} \leq V$ and $y_{r} \not \leq V$. Hence $y_{r} \leq 1-V$, which implies that $\mathrm{Cl}_{\alpha}\left(y_{r}\right) \leq \mathrm{Cl}_{\alpha}(1-V)=1-V$. That is, $\mathrm{Cl}_{\alpha}\left(y_{r}\right) \leq 1-\bigwedge\{U \in F \alpha O(X, \tau): V \leq U\}$. Hence there exists $U \in F \alpha O(X, \tau)$ such that $x_{t} \not \leq U$ and $\mathrm{Cl}_{\alpha}\left(y_{r}\right) \leq$ $U$. Hence $\mathrm{Cl}_{\alpha}\left(x_{t}\right) \leq 1-U$. Therefore, $y_{r} \not \leq \mathrm{Cl}_{\alpha}\left(x_{t}\right)$. That is, $\mathrm{Cl}_{\alpha}\left(x_{t}\right) \leq F \operatorname{Ker}_{\alpha}\left(x_{t}\right)$.

(5) $\rightarrow(1)$ : Let $U \in F \alpha O(X, \tau)$ and $x_{t} \leq U$. Then $\mathrm{Cl}_{\alpha}\left(x_{t}\right) \leq$ $F \operatorname{Ker}_{\alpha}\left(x_{t}\right) \leq U$. Hence $(X, \tau)$ is fuzzy $\alpha R_{0}$-space.

Corollary 3. A fuzzy topological space $(X, \tau)$ is fuzzy $\alpha R_{0^{-}}$ space if and only if $\mathrm{Cl}_{\alpha}\left(x_{t}\right)=F \operatorname{Ker}_{\alpha}\left(x_{t}\right)$ for all $x_{t} \in P t(X)$.

Proof. Suppose that $(X, \tau)$ is fuzzy $\alpha R_{0}$-space. Then by Theorem 10, $\mathrm{Cl}_{\alpha}\left(x_{t}\right) \leq F \operatorname{Ker}_{\alpha}\left(x_{t}\right)$ for all $x_{t} \in P t(X)$. Let $y_{r} \leq$ $F \operatorname{Ker}_{\alpha}\left(x_{t}\right)$. Then by Lemma 2, $x_{t} \in \operatorname{Cl}_{\alpha}(y) \leq F \operatorname{Ker}_{\alpha}\left(y_{r}\right)$. Hence $x_{t} \leq F \operatorname{Ker}_{\alpha}\left(y_{r}\right)$, which implies, by the same lemma, that $y_{r} \in \mathrm{Cl}_{\alpha}\left(x_{t}\right)$. Therefore, $\mathrm{Cl}_{\alpha}\left(x_{t}\right)=F \operatorname{Ker}_{\alpha}\left(x_{t}\right)$ for all $x_{t} \in \operatorname{Pt}(X)$. Conversely, it is obvious by Theorem 10 .

Theorem 11. For fuzzy topological space $(X, \tau)$, the following properties are equivalent:

(1) $(X, \tau)$ is fuzzy $\alpha R_{0}$-space;

(2) $x_{t} \leq \mathrm{Cl}_{\alpha}\left(y_{r}\right)$ if and only if $y_{r} \leq \mathrm{Cl}_{\alpha}\left(x_{t}\right)$ for all $x_{t}, y_{r} \in$ $P t(X)$.

Proof. (1) $\rightarrow(2)$ : Let $x_{t} \leq \mathrm{Cl}_{\alpha}\left(y_{r}\right)$. Since $(X, \tau)$ is fuzzy $\alpha R_{0^{-}}$ space, then, by Corollary $3, \operatorname{Cl}_{\alpha}\left(y_{r}\right)=F \operatorname{Ker}_{\alpha}\left(y_{r}\right)$. Hence by Lemma 2, $y_{r} \leq \mathrm{Cl}_{\alpha}\left(x_{t}\right)$. Similarly, we examine the converse.

$(2) \rightarrow(1)$ : Let $U \in F \alpha O(X, \tau)$ and $x_{t} \leq U$. If $y_{r} \not \leq U$, then $x_{t} \not \leq \mathrm{Cl}_{\alpha}\left(y_{r}\right)$. Then by $(2), y_{r} \not \leq \mathrm{Cl}_{\alpha}\left(x_{t}\right)$. Hence $\mathrm{Cl}_{\alpha}\left(x_{t}\right) \leq U$. That is, $(X, \tau)$ is fuzzy $\alpha R_{0}$-space.
Theorem 12. For fuzzy topological space $(X, \tau)$, the following properties are equivalent:

(1) $(X, \tau)$ is fuzzy $\alpha R_{0}$-space.

(2) $G=F \operatorname{Ker}_{\alpha}(G)$ whenever $G \in F \alpha C(X, \tau)$.

(3) if $G \in F \alpha C(X, \tau)$ and $x_{t} \leq G$, then $F \operatorname{Ker}_{\alpha}\left(x_{t}\right) \leq G$.

(4) $F \operatorname{Ker}_{\alpha}\left(x_{t}\right) \leq \mathrm{Cl}_{\alpha}\left(x_{t}\right)$ for all $x_{t} \in P t(X)$.

Proof. (1) $\rightarrow(2)$ : Let $G \in F \alpha C(X, \tau)$. It is clear that $G \leq$ $F \operatorname{Ker}_{\alpha}(G)$. Let $x_{t} \not \leq G$. Then $x_{t} \leq 1-G \in F \alpha O(X, \tau)$. Since $(X, \tau)$ is fuzzy $\alpha R_{0}$-space, then $\mathrm{Cl}_{\alpha}\left(x_{t}\right) \leq 1-G$. Then $\mathrm{Cl}_{\alpha}\left(x_{t}\right) \neg q G$, and by Lemma 1 we get that $x_{t} \not \leq F \operatorname{Ker}_{\alpha}(G)$. Therefore $G=F \operatorname{Ker}_{\alpha}(G)$.

$(2) \rightarrow(3)$ : In general, $A \leq B$ implies that $F \operatorname{Ker}_{\alpha}(A) \leq$ $F \operatorname{Ker}_{\alpha}(B)$. Therefore, it follows from (2) that $F \operatorname{Ker}_{\alpha}\left(x_{t}\right) \leq$ $F \operatorname{Ker}_{\alpha}(G)=G$.

$(3) \rightarrow(4)$ : Since $x_{t} \leq \mathrm{Cl}_{\alpha}\left(x_{t}\right)$ and $\mathrm{Cl}_{\alpha}\left(x_{t}\right) \in F \alpha C(X, \tau)$, then $F \operatorname{Ker}_{\alpha}\left(x_{t}\right) \leq \mathrm{Cl}_{\alpha}\left(x_{t}\right)$.

$(4) \rightarrow(1)$ : We show the implication by using the par (5) of Theorem 10. Let $x_{t} \in \operatorname{Pt}(X)$ and $y_{r} \leq \mathrm{Cl}_{\alpha}\left(x_{t}\right)$. Then by Lemma 2, $x_{t} \leq F \operatorname{Ker}_{\alpha}\left(y_{r}\right)$ and by (4), $F \operatorname{Ker}_{\alpha}\left(y_{r}\right) \leq$ $\mathrm{Cl}_{\alpha}\left(y_{r}\right)$. Hence $x_{t} \leq \mathrm{Cl}_{\alpha}\left(y_{r}\right)$ which implies, by Lemma 2, $y_{r} \leq F \operatorname{Ker}_{\alpha}\left(x_{t}\right)$. Then $\mathrm{Cl}_{\alpha}\left(x_{t}\right) \leq F \operatorname{Ker}_{\alpha}\left(x_{t}\right)$. Therefore, by Theorem $10,(X, \tau)$ is fuzzy $\alpha R_{0}$-space.

Definition 10. A fuzzy topological space $(X, \tau)$ is called fuzzy $\alpha R_{1}$-space if for every pair of fuzzy points $x_{t}, y_{r}$ in $X$ with $\mathrm{Cl}_{\alpha}\left(x_{t}\right) \neq \mathrm{Cl}_{\alpha}\left(y_{r}\right)$, there exists $U, V \in F \alpha O(X, \tau)$ such that $\mathrm{Cl}_{\alpha}\left(x_{t}\right) \leq U, \mathrm{Cl}_{\alpha}\left(y_{r}\right) \leq V$ and $U \neg q V$.

Theorem 13. A fuzzy topological space $(X, \tau)$ is fuzzy $\alpha R_{1}$ space if and only if for every pair of fuzzy points $x_{t}, y_{r}$ in $X$ with $F \operatorname{Ker}_{\alpha}\left(x_{t}\right) \neq F \operatorname{Ker}_{\alpha}\left(y_{r}\right)$, there exists $U, V \in F \alpha O(X, \tau)$ such that $\mathrm{Cl}_{\alpha}\left(x_{t}\right) \leq U, \mathrm{Cl}_{\alpha}\left(y_{r}\right) \leq V$ and $U \neg q V$.

Proof. Obvious, by Lemma 3.

Open Problem. Recently, the several authors studied the notion of pairwise openness and closedness as well as pairwise covers in order to study pairwise Lindelöf spaces [19], pairwise continuity and mappings [20], pairwise nearly Lindelöf spaces [21], pairwise weakly regular-Lindelf spaces [22], and the pairwise almost Lindelöf spaces in bitopological setting, see for example, [23-25] which were the extensions of some results due to Balasubramanian [26], Cammaroto and Santoro [27], and Fawakhreh and Kılıçman [28, 29]. It is an open problem to extend these new concepts to the bitopological spaces.

\section{Acknowledgments}

The authors thank the referee(s) for the helpful and significant comments that improved the paper substantially. The paper was prepared when the first author visited Putra University, Malaysia and thus the authors therefore gratefully acknowledge that this research was partially supported by the Putra University, Malaysia under the Science Fund Grant 0601-04-SF1050 and Research University Grant scheme 05-0109-0720RU. 


\section{References}

[1] L. A. Zadeh, "Fuzzy sets," Information and Computation, vol. 8, pp. 338-353, 1965.

[2] C. L. Chang, "Fuzzy topological spaces," Journal of Mathematical Analysis and Applications, vol. 24, pp. 182-190, 1968.

[3] J. A. Goguen, "The fuzzy Tychonoff theorem," Journal of Mathematical Analysis and Applications, vol. 43, pp. 734-742, 1973.

[4] T. Kubiak, On fuzzy topologies, Ph.D. thesis, A. Mickiewicz, Poznan, 1985.

[5] A. P. Šostak, "On a fuzzy topological structure," Rendiconti del Circolo Matematico di Palermo. Serie II, no. 11, pp. 89-103, 1985.

[6] M. S. Ying, "A new approach for fuzzy topology. I," Fuzzy Sets and Systems, vol. 39, no. 3, pp. 303-321, 1991.

[7] P. M. Pu and Y. M. Liu, "Fuzzy topology. I. Neighborhood structure of a fuzzy point and Moore-Smith convergence," Journal of Mathematical Analysis and Applications, vol. 76, no. 2, pp. 571-599, 1980.

[8] D. Zhang and L. Xu, "Categories isomorphic to FNS," Fuzzy Sets and Systems, vol. 104, no. 3, pp. 373-380, 1999.

[9] J. Fang, "I-FTOP is isomorphic to I-FQN and I-AITOP," Fuzzy Sets and Systems, vol. 147, no. 2, pp. 317-325, 2004.

[10] O. Njastad, "On some classes of nearly open sets," Pacific Journal of Mathematics, vol. 15, pp. 961-970, 1965.

[11] A. S. Bin Shahna, "On fuzzy strong semicontinuity and fuzzy precontinuity," Fuzzy Sets and Systems, vol. 44, no. 2, pp. 303308, 1991.

[12] J. Z. Shen, "Separation axiom in fuzzifying topology," Fuzzy Sets and Systems, vol. 57, no. 1, pp. 111-123, 1993.

[13] Y. Yue and J. Fang, "On separation axioms in I-fuzzy topological spaces," Fuzzy Sets and Systems, vol. 157, no. 6, pp. 780-793, 2006.

[14] H.-Y. Li and F.-G. Shi, "Some separation axioms in I-fuzzy topological spaces," Fuzzy Sets and Systems, vol. 159, no. 5, pp. 573-587, 2008.

[15] F. H. Khedr, F. M. Zeyada, and O. R. Sayed, "On separation axioms in fuzzifying topology," Fuzzy Sets and Systems, vol. 119, no. 3, pp. 439-458, 2001.

[16] F. S. Mahmoud, M. A. Fath Alla, and S. M. Abd Ellah, "Fuzzy topology on fuzzy sets: fuzzy semicontinuity and fuzzy semiseparation axioms," Applied Mathematics and Computation, vol. 153, no. 1, pp. 127-140, 2004.

[17] C. K. Wong, "Fuzzy points and local properties of fuzzy topology," Journal of Mathematical Analysis and Applications, vol. 46, pp. 316-328, 1974.

[18] Y.-M. Liu and M.-K. Luo, Fuzzy Topology, vol. 9 of Advances in Fuzzy Systems-Applications and Theory, World Scientific, River Edge, NJ, USA, 1997.

[19] A. Kılıçman and Z. Salleh, "On pairwise Lindelöf bitopological spaces," Topology and Its Applications, vol. 154, no. 8, pp. 16001607, 2007.

[20] A. Kılıçman and Z. Salleh, "Mapping and pairwise continuity on pairwise Lindelöf bitopological spaces," Albanian Journal of Mathematics, vol. 4, no. 2, pp. 31-47, 2010.

[21] Z. Salleh and A. Kılıçman, "Pairwise nearly Lindelöf spaces," in Proceedings of the 5th Asian Mathematical Conference, vol. 1, pp. 190-197, Malaysia, 2009.

[22] A. Kılıçman and Z. Salleh, "Pairwise weakly regular-Lindelöf spaces," Abstract and Applied Analysis, vol. 2008, Article ID 184243, 13 pages, 2008.
[23] A. Kılıçman and Z. Salleh, "Pairwise almost Lindelöf bitopological spaces," Malaysian Journal of Mathematical Sciences, vol. 1, no. 2, pp. 227-238, 2007.

[24] A. Kılıçman and Z. Salleh, "A note on pairwise continuous mappings and bitopological spaces," European Journal of Pure and Applied Mathematics, vol. 2, no. 3, pp. 325-337, 2009.

[25] A. Kılıçman and Z. Salleh, "On pairwise almost regularLindelöf spaces," Scientiae Mathematicae Japonicae, vol. 70, no. 3, pp. 285-298, 2009.

[26] G. Balasubramanian, "On some generalizations of compact spaces," Glasnik Matematički. Serija III, vol. 17(37), no. 2, pp. 367-380, 1982.

[27] F. Cammaroto and G. Santoro, "Some counterexamples and properties on generalizations of Lindelöf spaces," International Journal of Mathematics and Mathematical Sciences, vol. 19, no. 4, pp. 737-746, 1996.

[28] A. J. Fawakhreh and A. Kılıçman, "Mappings and some decompositions of continuity on nearly Lindelöf spaces," Acta Mathematica Hungarica, vol. 97, no. 3, pp. 199-206, 2002.

[29] A. J. Fawakhreh and A. Kılıçman, "Mappings and decompositions of continuity on almost Lindelöf spaces," International Journal of Mathematics and Mathematical Sciences, vol. 2006, Article ID 98760, 7 pages, 2006. 

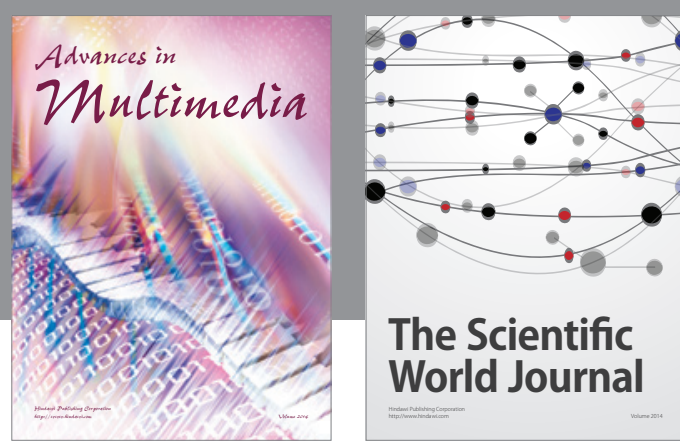

The Scientific World Journal
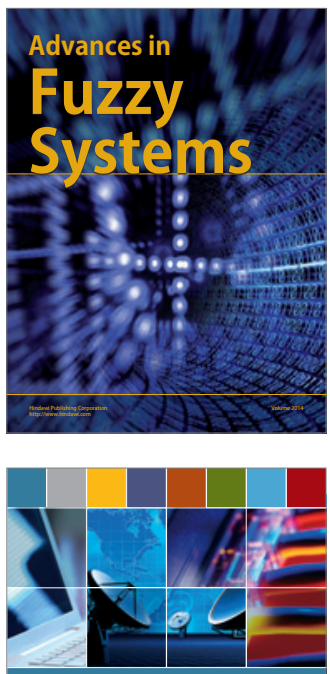

Computer Networks and Communications
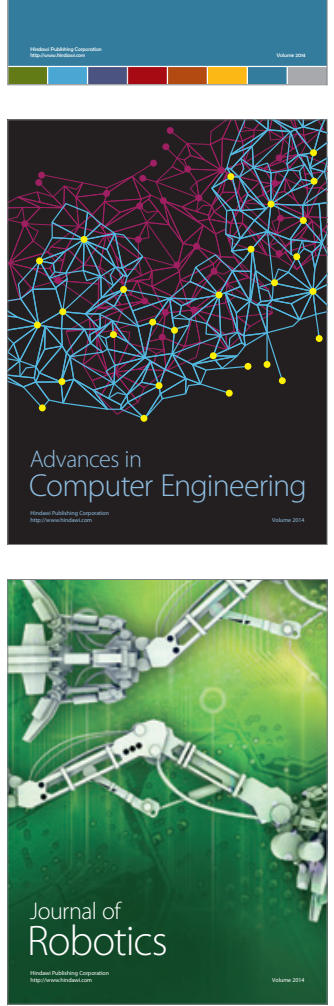
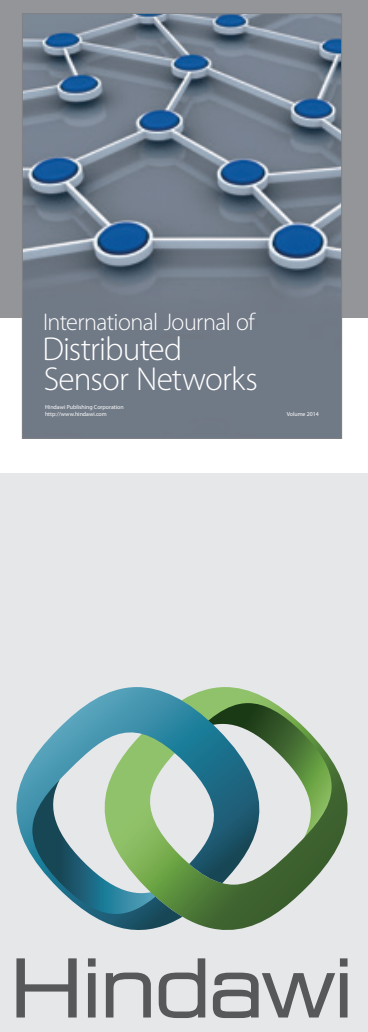

Submit your manuscripts at

http://www.hindawi.com
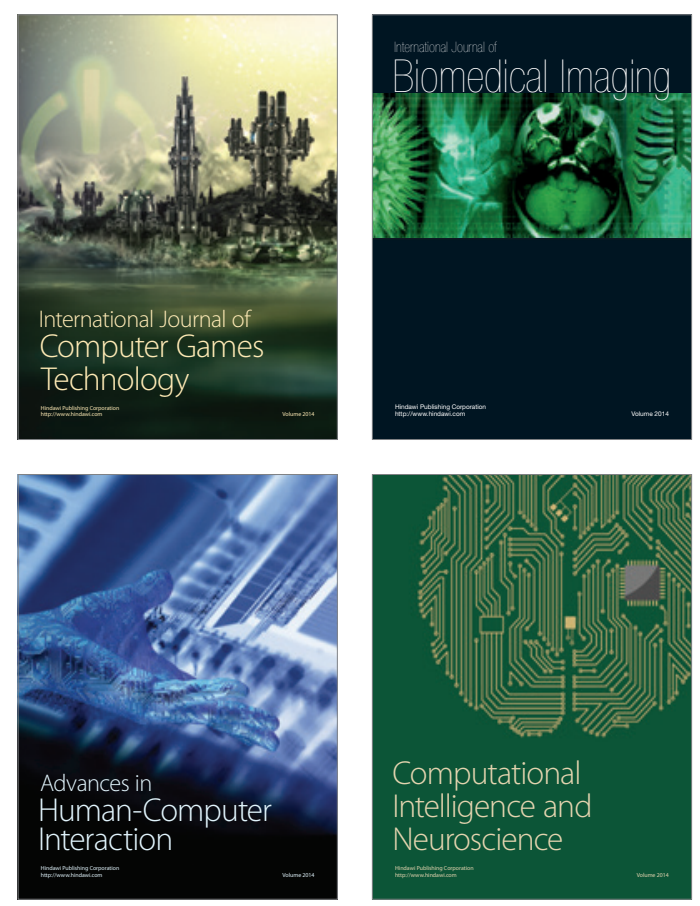
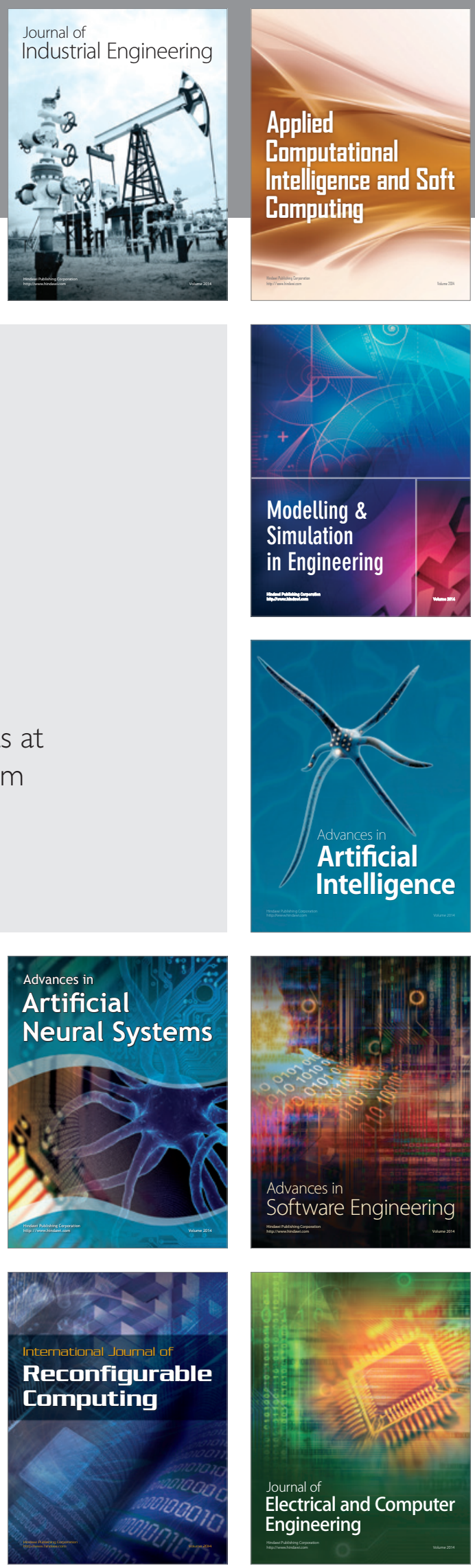